\title{
Uji efek ekstrak daun papaya (Carica papaya L.) terhadap kadar gula darah tikus Wistar (Rattus norvegicus) yang diinduksi aloksan
}

\author{
${ }^{1}$ Cynthia C. C. Senduk \\ ${ }^{2}$ Henoch Awaloei \\ ${ }^{2}$ Edward Nangoy
}

\author{
${ }^{1}$ Kandidat Skripsi Fakultas Kedokteran Universitas Sam Ratulangi Manado \\ ${ }^{2}$ Bagian Farmakologi dan Terapi Fakultas Kedokteran Universitas Sam Ratulangi Manado \\ Email: cynthiasenduk@yahoo.com
}

\begin{abstract}
Indonesia is a tropical country with more than 9,600 kinds of medicinal plants; one of them is papaya. Extract of papaya leaf (Carica papaya) is presumed to have hypoglycemia effect because it contains flavonoid, alkaloid, saponin, and tannin. This study aimed to evaluate the effect of papaya leaf extract on elevated blood glucose levels on Wistar rats induced with alloxan. This was an experimental study with 18 male Wistar rats as subjects, divided into 6 groups (3 rats in each group). Group 1, the negative control group, was given aquadest only. Group 2, the positive control group, was treated with alloxan $120 \mathrm{mg} / \mathrm{kg}$ body weight (BW) followed by novomix $0.2 \mathrm{iu} / 200 \mathrm{~g}$ BW. Group 3 and 4 were treated with alloxan $120 \mathrm{mg} / \mathrm{kg}$ BW followed by papaya leaf extract dosing $250 \mathrm{mg}$ and $500 \mathrm{mg} / \mathrm{kg}$ BW respectively. Group 5 and 6 were treated with papaya leaf extract dosing $250 \mathrm{mg}$ and 500 $\mathrm{mg} / \mathrm{kg}$ BW without alloxan induction. Blood glucose levels were measured on day 1 , day 2, and day 3 every six hours at $0,6,12,18$, and 24 hours. The results showed that $250 \mathrm{mg} / \mathrm{kg}$ BW and $500 \mathrm{mg} / \mathrm{kg}$ BW of papaya leaf extract could reduce the elevated blood glucose on Wistar rats for 12 hours after treatment. Conclusion: The extract of papaya leaves could reduce blood sugar levels in hyperglicemic Wistar rats induced by alloxan.
\end{abstract}

Keywords: papaya leaves (carica papaya L.), blood sugar levels, alloxan.

\begin{abstract}
Abstrak: Indonesia merupakan salah satu negara beriklim tropis yang memiliki banyak jenis tumbuhan. Sekitar 9.600 spesies tumbuhan merupakan tumbuhan yang berkhasiat obat, salah satunya ialah pepaya. Ekstrak daun pepaya (Carica papaya L.) diduga mempunyai efek hipoglikemia karena mengandung flavonoid, alkaloid, saponin, dan tannin. Penelitian ini bertujuan untuk menguji pengaruh pemberian ekstrak daun pepaya (Carica papaya L.) terhadap kadar gula darah tikus Wistar (Rattus norvegicus) yang diinduksi aloksan. Jenis penelitian ini eksperimental. Subyek penelitian yang digunakan ialah 18 ekor tikus Wistar jantan yang dibagi menjadi 6 kelompok (setiap kelompok terdiri dari 3 tikus). Kelompok 1 (K1) merupakan kelompok kontrol negatif hanya diberikan aquades; kelompok 2 (K2) merupakan kelompok kontrol positif diberikan aloksan dan novomix 0,2 iu/200 g BB; kelompok 3 (K3) dan kelompok 4 (K4) merupakan kelompok perlakuan diberikan aloksan kemudian ekstrak daun pepaya dengan dosis $250 \mathrm{mg} / \mathrm{kg}$ BB dan $500 \mathrm{mg} / \mathrm{kg}$ BB; kelompok 5 (K5) dan kelompok 6 (K6) merupakan kelompok perlakuan diberikan daun pepaya dengan dosis $250 \mathrm{mg} / \mathrm{kg}$ BB dan $500 \mathrm{mg} / \mathrm{kg}$ BB tanpa induksi aloksan. Data diperoleh dari pemeriksaan kadar gula darah dari semua kelompok tikus Wistar pada hari ke-1, ke-2, dan ke3 pada jam ke-0, 6, 12, 18, dan 24. Hasil penelitian menunjukkan bahwa pemberian ekstrak daun pepaya dengan dosis $250 \mathrm{mg}$ dan $500 \mathrm{mg} / \mathrm{kg}$ BB tikus berefek menurunkan kadar gula darah tikus wistar selama 12 jam pasca pemberian ekstrak daun pepaya. Simpulan: Ekstrak daun pepaya berpotensi memiliki efek dalam menurunkan kadar gula darah pada tikus Wistar.

Kata kunci: daun pepaya (carica papaya L.), kadar gula darah, aloksan
\end{abstract}


Diabetes Melitus (DM) merupakan penyakit dengan karakteristik peningkatan kadar gula darah. DM serta komplikasinya masih menjadi masalah utama kesehatan masyarakat di dunia. Menurut penelitian World Health Organization (WHO) pada tahun 2000 jumlah penderita DM tertinggi terdapat di India yaitu 31,7 juta penduduk. Indonesia dengan jumlah penderita DM 8,4 juta penduduk menduduki peringkat ke-4 tertinggi setelah India, China, dan Amerika Serikat. Prevalensi tertinggi DM terdapat di Daerah Istimewa Yogyakarta (2,6\%), Daerah Khusus Ibukota Jakarta (2,5\%), Sulawesi Utara (2,4\%), dan Kalimantan Timur (2,3\%). Penyuluhan kesehatan diperlukan untuk menambah pengetahuan penderita tentang penanganan DM. ${ }^{1,2}$ Salah satu pengobatan DM yaitu dengan pengobatan tradisional. Obat tradisional ialah bahan atau ramuan yang berupa bahan tumbuhan, bahan hewan, bahan mineral, sediaan sarian (galenik) atau campuran dari bahan tersebut yang digunakan masyarakat secara turun-temurun untuk pengobatan berbagai penyakit. $^{3}$

Indonesia merupakan negara beriklim tropis dengan keanekaragaman hayati terbesar kedua di dunia setelah Brazil. Indonesia memiliki sekitar 25.000-30.000 spesies tumbuhan yang merupakan $80 \%$ dari jenis tumbuhan di dunia dan 90\% dari jenis tumbuhan di Asia. ${ }^{4}$ Dari jumlah tersebut, sekitar 9.600 spesies tumbuhan merupakan tumbuhan yang berkhasiat obat dan sekitar 300 spesies sudah digunakan sebagai obat tradisional. ${ }^{3}$

Salah satu tumbuhan yang digunakan sebagai tumbuhan berkhasiat obat yaitu tumbuhan jenis pepaya (Carica papaya). Disamping sebagai tumbuhan yang dikonsumsi manusia maupun hewan, tumbuhan pepaya juga memiliki khasiat yang beragam diantaranya ekstrak air epikarp pepaya berefek terhadap penyembuhan luka dan biji pepaya berefek terhadap penurunan kadar kolesterol dan kadar gula darah. ${ }^{5-7}$

\section{METODE PENELITIAN}

Jenis penelitian ini ialah eksperimental yang dilakukan di Laboratorium Farmakologi dan Terapi serta Animal House Fakultas Kedokteran Universitas Sam Ratulangi Manado pada bulan September 2015-Januari 2016. Subjek yang digunakan ialah 18 ekor tikus Wistar jantan dengan berat badan 250-350g.

Persiapan penelitian meliputi alat untuk pemeliharaan hewan uji, pembuatan dan pemberian ekstrak daun papaya, pengukuran kadar gula darah $\left(A c c u_{\text {check }}\right.$ electronik glucose test, Accu $_{\text {check }}$ electronik blood test strip), dan stopwatch. Bahan yang digunakan terdiri dari daun pepaya, etanol 80\%, aloksan, analog insulin, aquades, dan pakan AD2.

Aloksan dengan dosis $120 \mathrm{mg} / \mathrm{kgBB}$ diberikan secara intraperitonial untuk menginduksi keadaan hiperglikemi pada tikus. Analog insulin diberikan subkutan pada bagian punggung tikus dengan dosis $1,0 \mathrm{iu} /$ kgBB. $^{8}$

Pemberian ekstrak daun pepaya dengan dosis $250 \mathrm{mg} / \mathrm{kg}$ BB dan $500 \mathrm{mg} / \mathrm{kg}$ BB secara oral diharapkan dapat menurunkan kadar glukosa darah pada tikus Wistar. Dosis $250 \mathrm{mg} / \mathrm{kg}$ BB, 500 $\mathrm{mg} / \mathrm{kg} \mathrm{BB}$, dan $1000 \mathrm{mg} / \mathrm{kg}$ BB ekstrak daun pepaya tidak menunjukkan efek toksis yang bermakna sehingga penulis menentukan dosis ekstrak daun pepaya yang akan digunakan pada penelitian ini ialah 250 mg/kg BB dan 500 mg/kg tikus. ${ }^{9}$ Hewan uji dibagi dalam enam kelompok. Sebelum pengukuran pada hari pertama (H1), semua tikus dipuasakan selama 12 jam mulai jam 6 pagi sampai jam 6 sore. Setelah 12 jam kadar glukosa darah puasa semua tikus diperiksa, setelah itu tiga kelompok tikus hanya diberikan aquades sedangkan tiga kelompok tikus lainnya diberikan aloksan dengan dosis $120 \mathrm{mg} / \mathrm{kgBB}$ tikus untuk menginduksi kerusakan sel B pankreas sehingga glukosa darah tikus meningkat. Kadar glukosa darah semua tikus diperiksa kembali pada hari kedua (H2) setelah 24 jam pemberian aloksan dan pada awal hari ketiga (H3) jam ke-0. Setelah kadar glukosa darah diukur, semua kelompok tikus diberikan perlakuan. Kelompok kontrol positif diberikan analog insulin 
dengan dosis 1,0 iu/ $/ \mathrm{kBBB}^{8}$, dua kelompok yang sudah diinduksi dengan aloksan diberikan ekstrak daun pepaya dengan dosis $250 \mathrm{mg} / \mathrm{kg}$ BB dan $500 \mathrm{mg} / \mathrm{kg}$ BB dan dua kelompok lainnya hanya diberikan ekstrak daun pepaya dengan dosis 250 $\mathrm{mg} / \mathrm{kg}$ BB dan $500 \mathrm{mg} / \mathrm{kg}$ BB tanpa pemberian aloksan. Kadar glukosa darah pada semua tikus kemudian diperiksa pada jam ke-6, 12, 18, dan 24. Semua sampel darah diambil dari pemotongan ujung ekor tikus dan kadar glukosa darah diukur dengan glukometer.

\section{HASIL PENELITIAN}

Pengukuran kadar glukosa darah dilakukan sebanyak 7 kali yaitu: H1, H2 dan H3 pada jam ke-0 sebelum perlakuan dan jam ke-6, 12, 18, dan 24 setelah perlakuan. Kelompok 1 (K1) merupakan kelompok kontrol negatif yaitu kelompok yang hanya diberikan aquades; kelompok 2 (K2) merupakan kelompok kontrol positif yang diberikan aloksan dan analog insulin; kelompok 3 (K3) dan kelompok 4 (K4) merupakan kelompok perlakuan yang diberikan aloksan kemudian ekstrak daun pepaya dengan dosis $250 \mathrm{mg} / \mathrm{kg}$ BB dan $500 \mathrm{mg} / \mathrm{kg}$ BB; kelompok 5 (K5) dan kelompok 6 (K6) merupakan kelompok perlakuan yang diberikan dosis daun pepaya dengan dosis $250 \mathrm{mg} / \mathrm{kg}$ BB dan $500 \mathrm{mg} / \mathrm{kg}$ BB tanpa diberikan aloksan. Hasil pengukuran seluruh kelompok dapat dilihat pada Tabel 1.

Tabel 1. Hasil Pengukuran Kadar Gula Darah Seluruh Kelompok Perlakuan

\begin{tabular}{|c|c|c|c|c|c|c|c|c|}
\hline \multirow[b]{2}{*}{ Kelompok } & \multirow{2}{*}{ Hewan Uji } & \multirow{2}{*}{$\mathrm{H} 1$} & \multirow{2}{*}{$\mathrm{H} 2$} & \multicolumn{5}{|c|}{ H3 } \\
\hline & & & & $\begin{array}{c}0 \\
(\mathrm{mg} / \mathrm{dL})\end{array}$ & $\begin{array}{c}6 \\
(\mathrm{mg} / \mathrm{dL}) \\
\end{array}$ & $\begin{array}{c}12 \\
(\mathrm{mg} / \mathrm{dL})\end{array}$ & $\begin{array}{c}18 \\
(\mathrm{mg} / \mathrm{dL})\end{array}$ & $\begin{array}{c}24 \\
(\mathrm{mg} / \mathrm{dL})\end{array}$ \\
\hline \multirow{4}{*}{$\mathrm{K} 1$} & Tikus N1 & 97 & 96 & 86 & 80 & 92 & 100 & 93 \\
\hline & Tikus N2 & 94 & 87 & 95 & 92 & 90 & 95 & 89 \\
\hline & Tikus N3 & 92 & 107 & 92 & 86 & 96 & 92 & 112 \\
\hline & Rata-rata & 94,3 & 96,7 & 91 & 86 & 92,67 & 95,67 & 98 \\
\hline \multirow{4}{*}{$\mathrm{K} 2$} & Tikus P1 & 73 & 120 & 466 & 435 & 257 & 189 & 160 \\
\hline & Tikus P2 & 81 & 189 & 514 & 480 & 263 & 167 & 135 \\
\hline & Tikus P3 & 91 & 213 & 600 & 517 & 243 & 132 & 102 \\
\hline & Rata-rata & 81,7 & 174 & 526,7 & 477,3 & 254,3 & 162,7 & 132,3 \\
\hline \multirow{4}{*}{$\mathrm{K} 3$} & Tikus A1 & 87 & 103 & 355 & 222 & 200 & 345 & 461 \\
\hline & Tikus A2 & 74 & 120 & 382 & 309 & 230 & 337 & 371 \\
\hline & Tikus A3 & 87 & 189 & 491 & 344 & 265 & 336 & 450 \\
\hline & Rata-rata & 80,5 & 137,3 & 409,3 & 291,7 & 231,7 & 339,3 & 427,3 \\
\hline \multirow{4}{*}{$\mathrm{K} 4$} & Tikus B1 & 78 & 268 & 600 & 436 & 210 & 394 & 395 \\
\hline & Tikus B2 & 86 & 112 & 341 & 175 & 126 & 191 & 230 \\
\hline & Tikus B3 & 83 & 153 & 403 & 240 & 175 & 257 & 340 \\
\hline & Rata-rata & 82,3 & 177,7 & 448 & 283,7 & 170,3 & 280,7 & 321,7 \\
\hline \multirow{4}{*}{$\mathrm{K} 5$} & Tikus C1 & 93 & 115 & 90 & 80 & 77 & 92 & 98 \\
\hline & Tikus C2 & 84 & 101 & 91 & 90 & 80 & 86 & 90 \\
\hline & Tikus C3 & 84 & 98 & 90 & 85 & 71 & 90 & 116 \\
\hline & Rata-rata & 87 & 104,7 & 90,3 & 85 & 76 & 89,3 & 101,3 \\
\hline \multirow{4}{*}{ K6 } & Tikus D1 & 78 & 104 & 103 & 81 & 80 & 88 & 72 \\
\hline & Tikus D2 & 87 & 83 & 100 & 72 & 78 & 91 & 81 \\
\hline & Tikus D3 & 84 & 103 & 111 & 83 & 77 & 85 & 73 \\
\hline & Rata-rata & 83 & 96,67 & 104,7 & 78,67 & 78,3 & 88 & 75,3 \\
\hline
\end{tabular}

\section{BAHASAN}

Penelitian yang dilakukan ialah penelitian eksperimental dengan hewan uji berupa 18 ekor tikus wistar yang diberi perlakuan yaitu ekstrak daun pepaya. Penelitian ini bertujuan untuk mengetahui 
pengaruh pemberian ekstrak daun pepaya terhadap kadar gula darah tikus wistar yang diinduksi aloksan.

Hasil pengukuran kadar gula darah pada K1 yaitu kelompok kontrol negatif yang hanya diberikan aquades, dari $\mathrm{H} 1$ sampai dengan H3 tidak menunjukkan peningkatan atau penurunan yang bermakna. Kadar gula darah seluruh tikus yang diukur selama 3 hari mempunyai ratarata yaitu 86-98 mg/dL. Kadar gula darah ketiga tikus masih dalam batas normal yaitu $50-135 \mathrm{mg} / \mathrm{dL}{ }^{10}$

Pada K2 yaitu kelompok kontrol positif yang diberikan aloksan, kadar gula darah tikus meningkat pada $\mathrm{H} 2$ dan $\mathrm{H} 3$ jam ke-0 dan setelah pemberian analog insulin kadar gula darah tikus menurun. Kadar glukosa darah mengalami penurunan karena analog insulin berikatan dengan reseptor insulin yang meningkatkan ambilan glukosa darah dan menghambat pengeluaran glukosa oleh hepar. Analog insulin yang digunakan yaitu Novomix. Novomix adalah insulin campuran dua macam insulin yang kerja cepat dan kerja menengah. Novomix memiliki mula kerja 10-20 menit setelah injeksi subkutan dan lama kerja kurang dari 24 jam. ${ }^{8}$

Pada K3 dan K4 yaitu kelompok perlakuan yang diberikan ekstrak daun papaya. Pada pemberian ddengan dosis 250 $\mathrm{mg} / \mathrm{kg}$ BB didapatkan hasil penurunan kadar gula darah lebih sedikit dibandingkan dengan pada dosis $500 \mathrm{mg} / \mathrm{kg}$ BB. Penurunan kadar gula darah pada tikus wistar salah satunya disebabkan karena adanya kandungan zat aktif dalam daun pepaya yaitu flavonoid, tannin, saponin, dan alkaloid yang berefek hipoglikemia. Selain itu, zat aktif yang terkandung dalam daun pepaya juga berperan merangsang pelepasan insulin dari sel beta pancreas dan pelepasan somatostatin tetapi menekan sekresi glukagon. ${ }^{11}$

Pada K5 dan K6 yaitu kelompok kontrol positif yang diberikan insulin serta perlakuan satu dan perlakuan dua yang diberikan ekstrak daun pepaya, 24 jam setelah perlakuan kadar gula darah mulai meningkat kembali hingga 96 jam setelah perlakuan tetapi tidak melebihi kadar gula darah saat 48 jam pasca pemberian aloksan dan sebelum diberikan perlakuan. Dalam hal ini kerusakan pada pulau Langerhans tikus hiperglikemik berkurang dengan pemberian ekstrak daun papaya. Laporan lain juga menyatakan bahwa pada tikus diabetes melitus pemberian ekstrak daun pepaya efektif dalam regenarasi sel dan pemulihan pulau Langerhans. Pada K5 dan K6 yaitu kelompok perlakuan tiga dan perlakuan empat tidak menunjukkan efek hipoglikemik yang bermakna setelah diberikan perlakuan. Penelitian Juarez ${ }^{12}$ juga menunjukkan bahwa ekstrak daun pepaya meningkatkan produksi insulin, tanpa efek hipoglikemik yang bermakna pada tikus non-diabetes.

\section{SIMPULAN}

Berdasarkan hasil penelitian dan bahasan dapat disimpulkan bahwa ekstrak daun pepaya dengan dosis $250 \mathrm{mg} / \mathrm{kg}$ BB tikus dan $500 \mathrm{mg} / \mathrm{kg}$ BB tikus mempunyai pengaruh menurunkan kadar gula darah tikus Wistar selama 12 jam pasca pemberian ekstrak daun pepaya.

\section{SARAN}

Perlu dilakukan penelitian dengan waktu lebih panjang untuk mengetahui lebih lanjut perkembangan kadar gula darah tikus yang telah diberikan perlakuan.

Perlu dilakukan penelitian lebih lanjut mengenai kandungan kimia daun pepaya.

\section{DAFTAR PUSTAKA}

1. Pusat Data dan Informasi Kementerian Kesehatan RI. Status dan Analisis Diabetes. 2014. [cited 18 Sep 2015]. Available from: http://www.depkes. go.id/download.php?file=download/p usdatin/infodatin/infodatindiabetes.pdf

2. National Institute of Diabetes and Digestive and Kidney Diseases. Your Guide to Diabetes: Type 1 and Type 2 [cited 2015 Sep 18]. Available from: http://www.niddk.nih.gov/healthinfor mation/health-topics/Diabetes/yourguide-diabetes/Documents/ YourGuide2Diabetes_508.pdf 
3. Departemen Kesehatan Republik Indonesia. Kebijakan Obat Nasional. Jakarta, 2007; p. 8-18.

4. Dewoto HR. Pengembangan Obat Tradisional Indonesia Menjadi Fitofarmaka. Maj Kedokt Indon. 2007;57:205.

5. 100 Plus herbal Indonesia Bukti Ilmiah dan Racikan. Jakarta: Trubus Swadaya; p. 480-2.

6. Anuar NS, Zahari SS, Taib IA, Rahman MT. Effect of Green and Ripe Carica Papaya Epicarp Extracts on Wound Healing and During Pregnancy. Food and Chemical Toxicology 2008;46:2384-9.

7. Olagunju JA, Adeneye AA. Preliminary Hypoglycemic and Hypolipidemic Activities of the Aqueous Seed Extract of Carica Papaya Linn. in Wistar Rats. Biology and Medicine. 2009;1:1-10.

8. NovoMix 30 FlexPen 100 units/ml, suspension for injection in a pre-filled pen. 2016 [cited 2016 Jan 3]. Available from: https://www.medicines.org.uk/emc/m edicine/8475

9. Santi TD. Uji Toksisitas Akut dan Efek Antiinflamasi Ekstrak Metanol dan Ekstrak n-Heksana Daun Pepaya (Carica papaya L.). Pharm Sci Res. 2015;2:101-14.

10. Taylor \& Francis Group. The Rat. In: Gad SC, editor. Animal Models in Toxicology (2nd ed). New York: CRC, 2007; p. 211.

11. Davis SN, Granner DK. Insulin, oral hypoglycemic agents, and the pharmacology of the endocrine pancreas. Goodman \& Gilman's The Pharmacological Basis of Therapeutics. New York: McGrawHill, 1996; 1468-1517.

12. Juarez IE, Juan CDZ, Jorge LBC, Pedro HMO, Andres ECR, Carlos ATZ, et al. Hypoglycemic effect of Carica papaya leaves in streptozotocininduced diabetic rats. BMC Complementary and Alternative Medicine. 2012;12:1-12. 